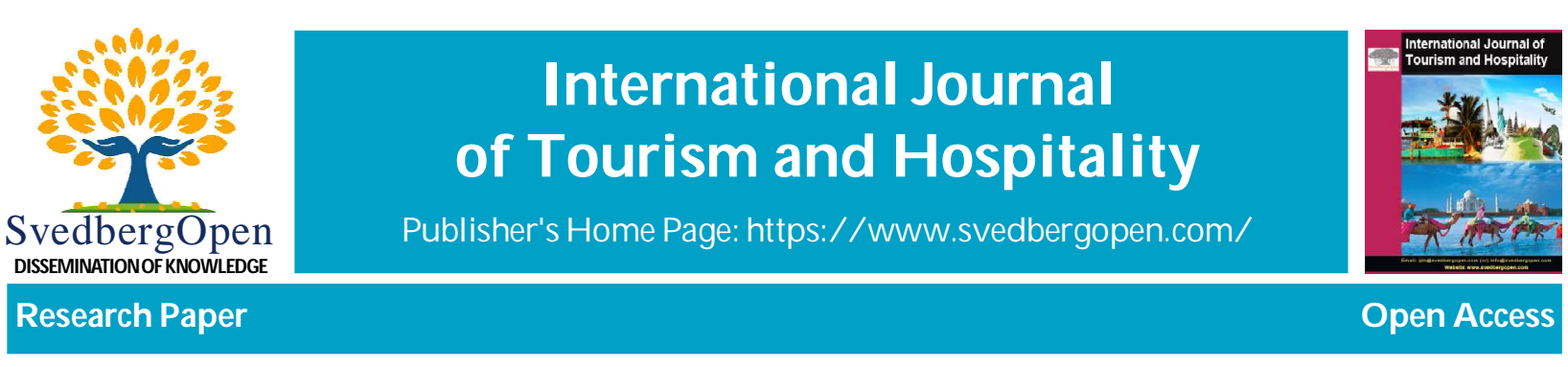

\title{
Community Involvement in Tourism Development
}

\author{
Chico, Maria Isabel C. ${ }^{1 *}$, Atienza, Mark Die M. ${ }^{2}$, Magbitang, Marvin, M. ${ }^{3}$, Retuerma, Myra, D. ${ }^{4}$ and Sanchez, Cielito, H. \\ ${ }^{1}$ Bulacan State University, Malolos, Bulacan, Philippines. E-mail: maisabel.chico@bulsu.edu.ph \\ ${ }^{2}$ Bulacan State University, Malolos, Bulacan, Philippines. E-mail: markdie.atienza@bulsu.edu.ph \\ ${ }^{3}$ Bulacan State University, Malolos, Bulacan, Philippines. E-mail: marvin.magbitang@bulsu.edu.ph \\ ${ }^{4}$ Bulacan State University, Malolos, Bulacan, Philippines. E-mail: retuermamyra@gmail.com \\ ${ }^{5}$ Bulacan State University, Malolos, Bulacan, Philippines. E-mail: cielito.sanchez@bulsu.edu.ph
}

\section{Article Info}

Volume 1, Special Issue 1, December 2021

Received : 14 August 2021

Accepted : 19 November 2021

Published : 05 December 2021

https://doi.org/10.51483/IJTH.1.S1.2021.S17-S2 1

\begin{abstract}
This study seeks to analyze the role of Hagonoy residents and their support for tourist development in the Municipality of Hagonoy, Bulacan Province, Philippines. As a result, it attempted to respond to the amount of community engagement in terms of cooption, compliance, consultation, collaboration, collective action, and co-learning. The study also highlighted the characteristics that influence community participation in tourist development.

Keywords: Tourism development, Community engagement, Community participation, Descriptive research

(C) 2021 Chico, Maria Isabel C. et al. et al. This is an open access article under the CC BY license (https://creativecommons.org/licenses/by/4.0/), which permits unrestricted use, distribution, and reproduction in any medium, provided you give appropriate credit to the original author(s) and the source, provide a link to the Creative Commons license, and indicate if changes were made.
\end{abstract}

\section{Introduction}

The tourism industry is often referred to as the largest industry in the world and is seen as a means of achieving sustainable development and represents significant economic, environmental and sociocultural opportunities for many local communities (Sharpley, 2002). According to the World Travel and Tourism Council (WTTC, 2008), tourism accounts for nearly $10 \%$ of the world's GDP comprising \$5.89 tn in economic activity and is expected to nearly double by 2018 . Harrill and Potts (2003), assumed that "tourism is an invisible industry, encompassing transportation, loading, and entertainment. Unfortunately, tourism is also invisible to many planners, so tourism development is often left to private developers and leisure service providers". Tourism is also the sum of the phenomena and links arising from the interaction of tourists, governments and local communities in the process of attracting and hosting these tourists and other visitors. Tourism research has also recently become a priority research subject in community development research (Galston and Baehler, 1995). Tourism is undoubtedly important at the local, national and international level. It should not be a core element of the economy of the community, but is better suited to playing an additional role in helping to diversify the economic activities of the community (Godfrey and Clarke, 2000). Tourism has become a source of revenue for many communities seeking ways to improve their livelihoods. Clearly, tourism and its impact is a multi-dimensional phenomenon that encompasses economic, social, cultural, ecological, environmental and political forces (Singh et al., 2003).

A sense of community is a key term used in the development of tourism. The sense of community is that an individual's sense of duty and commitment to other members of the community develops over time through the

* Corresponding author: Chico, M arialsabel C., Bulacan StateU niversity, M al ol os, Bulacan,P Pilippines. E-mail: maisabel.chico@bulsu.edu.ph 
understanding of collective values, beliefs and interests among community members. The sense of community is also a sense of belonging to the community (Bowen et al., 2003). Sarason (1974) defined the sense of community as the interdependence between individuals and communities. Bopp et al. (2000, p. 113) defines sense of community in the following way: "sense of community refers to the quality of human relationship that makes it possible for people to live together in a healthy and sustainable way". The importance and need for community awareness and participation in building strong capacity communities for tourism development cannot be ignored (Aref et al., 2010).

Community participation can be seen as a process in which community residents have a voice and a choice to participate in issues affecting their lives. Whether or not a community participates is determined by a variety of factors. One such factor is the reluctance to participate because the members of the community do not trust each other. Community participation can therefore be enhanced by addressing barriers to participation while at the same time taking the necessary steps to promote the principles of sustainable participation (Theron, 2005). Community participation in tourism development processes can promote and uphold local culture, tradition, knowledge and skills and create pride in community heritage (Lacy et al., 2002). The aim of community participation is to improve communication between stakeholders in order to facilitate better decision-making and sustainable development (Nampila, 2005).Community participation also is the mechanism for active community involvement in partnership working, decision making and representation in community structures (Chapman and Kirk, 2001). It should be noted that community participation often involves the involvement of people or the community in government. However, this study emphasized the participation of the community as part of the involvement of local people in tourism development processes. Without participation, there is clearly no partnership, no development and no program. The lack of community participation in decision-making to implement tourism development can therefore lead to a failure in community development (Miranda, 2007). Community participation increases people's sense of control over issues that affect their lives and also promotes self-confidence and self-awareness (Nampila, 2005). Levi and Litwin (1986) stated that community participation is also seen as the creation of a democratic system and a procedure to enable community members to become actively involved and to take responsibility for their own development, to share equally in the fruits of community development and to improve their decision-making powers. Community participation provides a sense of community to take responsibility for oneself and others, and a willingness to share and interact.

The Municipality of Hagonoy is one of the municipalities in the province of Bulacan in Central Luzon, with a land area of $103.10 \mathrm{~km} 2$ or $39.81 \mathrm{sq} \mathrm{mi}$, which covers 3.69\% of Bulacan's total area. According to the Philippines Statistics Authority, Hagonoy Bulacan has a population of 129,807 people as of 2015. With Hagonoy's coastal nature and abundant water resources, the local community's main source of livelihood depends on the fishing industry. According to the Commission of Audit, Hagonoy ranked as the 8th richest municipality in Bulacan on the 2010 Annual Financial Report; it shows how the residents of Hagonoy are hardworking, which is why local communities have an important role to play in the development of tourism. In tourism growth, the community should be supportive as they are considered to be legitimate and moral stakeholders. To increase the interest and trust of local people in the tourism industry, the local community must be actively involved in planning the development as they may be of help as they have information that only the locals have first handed experience.

Tourism has been one of the largest industries in the world and 2012; visitor arrivals exceed the 1 billion mark for the first time in history with more than millions of visitors crossing borders every month. With the forecasted growth in tourism, the promise of economic generation promised developed and developing countries to create policies to generate profit from tourism. In the case of the Philippines, the desire to increase tourism development is a national priority, and marketing campaigns are raised for the development of new tourism zones. Given that many tourist destinations in the country are being redeveloped, research into developing Hagonoy as a tourist destination is raised.

To this concern, this research attempts to assess the role of the residents' of Hagonoy and their support regarding the tourism development in the Municipality of Hagonoy, Bulacan Province in the Philippines. Thus it sought to answer the level of community involvement in terms of co-option, compliance, consultation, cooperation, collective action, and co-learning. The study also identified the factors influencing community involvement in tourism development.

\section{Methodology}

This study used a descriptive research design in validating and conceiving the answers in the research problems, and quantitative method will also be utilized. Descriptive research involves the description, recording, and interpretation of the presented information and details that focuses on the prevailing conditions, trends, and cause-effect relationships, and proceeding with an adequate and accurate interpretation about the data with or without the aid of statistical formula. 
In obtaining the assessment on the community involvement in tourism development in the Municipality of Hagonoy, quantitative design will also be utilized. Quantitative research is defined as a systematic investigation of phenomena by gathering quantifiable data and performing statistical, mathematical, or computational techniques. Through the use of quantitative design, the results of the data will be accurate, unbiased, and can be both favorable and unfavorable to the organization.

The respondents of this study were chosen through the use of purposive sampling as it is the most convenient sampling method to use based on the purpose of the study. There were total of 100 respondents in the data collection. They are all residents of Hagonoy who have direct knowledge in the community and tourism development of the municipality. Included in the samples are food and souvenir vendors, tourist guides, tourism students and local residents.

In obtaining the data of this research, the researcher used a self-made structured questionnaire. The questionnaire was divided into two parts: (1) the first part contains the demographic profile of the respondents; and (2) the second part is the survey proper. The decision to use questionnaires in the primary data collection is motivated by the fact they are quite inexpensive to administer and enable one to gather the information needed from a great number of participants within a short time-frame. Secondly, the difficulties that may have occurred using other methods such as interviews and focus groups are eliminated. The subjects listed in the questionnaire also provide opportunity to the respondents, to freely express their views and opinions.

In this regard, confidentiality and anonymity play an important role in terms of obtaining access to respondents. It is also crucial to underscore that no questions were asked of the respondents revealing their names and other personal information.

During the data gathering procedure, survey questionnaire was distributed among the respondents and answers were interpreted using percentage formula, frequencies and weighted mean, and $t$-test.

\section{Results}

The findings of the study were summarized according to the statement of the problems stated. Out of 100 respondents, $76 \%$ are ages $15-25,21 \%$ are ages 26-25, and 3\% are 36 years old and above. Most of the respondents are millennial that are expected to have innovative ideas. From 100 respondents, $60 \%$ are female and $40 \%$ are male. The data shows that most of the respondents are female as they are mostly available in time of conducting the survey. The respondents consisted of 100 local residents from Hagonoy, Bulacan, wherein only 6\% of them are married while $94 \%$ are single and able to fully engage with tourism development. Out of 100 respondents, $10 \%$ are high school graduate, $42 \%$ are college graduate, and $29 \%$ are undergraduate. On the other hand, deficiency is not a hindrance on having a part in community development. On the survey conducted, $61 \%$ are unemployed and $39 \%$ of them are employed which shows that the local residents are willing to take part with the local government for the tourism and community development as well.

Co-option got a 3.94 total mean which in verbal interpretation is Agree. This Agree by the respondents indicates that the community should be involved in the development progress. The data gathered probe that the respondents strongly agree that people can fully engage with the development progress with the help of set of rules as it got a total mean of 4.53. On the survey conducted, consultation's total mean is 4.49 which in verbal interpretation is Strongly Agree. This means people believe that through formally consulting them or discussing the development progress, they could take part of it. Based on the gathered data, 4.47 is the total mean of cooperation as the respondents believe that working together with the local government will not mislead the success of community and tourism development. This collaborative action got 4.31 total mean which represents that the respondents strongly agree to take an action together with the other local agencies to perform development process. Co-Learning can be interpreted that the respondents Strongly Agree that the local government and local residents are both involved in learning how to increase the quality of local tourism, to provide accurate information to the tourist and teaching culture through interactive activities with the help of the local as its total mean is 4.41 .

From the scale of not at all influential to extremely influential, the factors influencing community involvement in tourism development got a total mean of 2.235 or Slightly Influential. The given factors are: (1) Tourism helps to develop local economy; (2) Tourism helps to boost national cultural exchange; (3) Tourism creates a large number of jobs and income for local residents; (4) Tourism preserves and develops local culture; (5) Tourism enhances the quality of life of local residents; and (6) Tourism helps to raise the awareness of local residents. From the six factors, the "Tourism preserves and develops local culture" rank first with its 2.27 mean. This means that relying on the importance of local culture of the municipality they are captive to participate in tourism development of Hagonoy, Bulacan. 
The data gathered shows that there is only 0.0175511566 Multiple $R$, or the significant relationship between the level of community involvement and factors influencing community involvement have a very weak correlation.

\section{Discussion}

The researcher found that the age range of 15-25 received the highest respondents of $71 \%$, followed by the age range of 26-35 which made up $21 \%$ of the respondents. We can conclude that the respondents with the age range of 15-25 have more desire on being active and having a voice in the community involvement.

Regarding the level of community participation. The result of the findings revealed that the participants Strongly Agree that the community should have a place in the local government where working together and listening to the local people's suggestions and/or opinions will help the success of the development process and improve the quality of service that the local tourism can offer.

Out of six factors, the question "Tourism preserves and develop local culture" received the most vote as Slightly Influential. We can conclude that the local residents are willing to be involved in any development when it comes to preserving the local culture that has been passed down from generation to generation.

\section{Conclusion}

The communities in Hagonoy, Bulacan should partake in tourism development by obtaining strategic partnerships with the existing tourism government sector. Residents should be included in key progress measurement and decisionmaking activities by organizing community meetings of local citizens, using the local media as a communication platform, and analyzing data of local industries and also be empowered to determine what types of tourism they want to grow in their community, as well as how tourism potential benefits will be shared among diverse participants. Training and information programs should include the community members, with the goal of encouraging them to become more immersed in tourism development as startups and executives, but also as citizens with the right to live in a greater and comfortable environment. Authorities should consider a financial compensation framework to encourage local communities to engage in the tourism industry. As a result, local communities will have more job opportunities, unemployment will be reduced, quality of life will improve, and they will be much more cooperative of tourism development.

Though this study is limited to Hagonoy Bulacan's local communities, similar findings in other areas of Bulacan and other developing provinces are required. Such studies would serve as a foundation for correlation and would help establish the generalizability of the findings in the context of specific provinces or regions. Based on an analysis for the factors influencing community involvement in tourism development, it appears that factors obtained a descriptive measure of slightly influential, implying that researchers should focus on the attributes that have a strong influence on community involvement.

\section{References}

Aref, F. (2010). Residents’ Attitudes towards Tourism Impacts: A Case Study of Shiraz, Iran. Tourism Analysis, 15(2), 253261.

Aref, F., Ma'rof, R., and Sarjit, S.G. (2010). Community Capacity Building: A Review of its Implication in Tourism Development. Journal of American Science, 6(1), 172-180.

Bopp, M., GermAnn, K., Bopp, J., Baugh Litt1ejohns, L. and Smith, N. (2000). Assessing Community Capacity for Change.

Bowen, G.L., Mancini, J.A., Martin, J.A., Ware, W.B. and Nelson, J.P. (2003). Promoting the Adaptation of Military Families: An Empirical Test of a Community Practice Model. Family Relations, 52, 33-44.

Chapman, M. and Kirk, K. (2001). Lessons for Community Capacity Building: A Summary of the Research Evidence. Retrieved 2, October, 2007, from http://www.scothomes. gov.uk/pdfs/pubs/260.pdf

Galston, W.A. and Baehler, K.J. (1995). Rural Development in the United States: Connecting Theory, Practice and Possibilities. Washington, D.C: Island Press.

Godfrey, K. and Clarke, J. (2000). The Tourism Development Handbook: A Practical Approach to Planning and Marketing. London: Continuum. 
Harrill, R. and Potts, T. (2003). Tourism Planning in Historic Districts: Attitudes Toward Tourism Development in Charleston. Journal of the American Planning Association, 69(3), 233.

Lacy, T.D., Battig, M., Moore, S. and Noakes, S. (2002). Public / Private Partnerships for Sustainable Tourism. In Delivering a Sustainability Strategy for Tourism Destinations: Asia Pacific Economic Cooperation Apec Tourism Working Group.

Levi, Y. and Litwin, H. (1986). Community and Cooperations In Participatory Development. Aldershot: Gower.

Miranda, E.M. (2007). Gang Injunctions And Community Participation. University of Southern California.

Nampila, T. (2005). Assessing Community Participation-The Huidare Informal Settlement. University of Stellenbosch.

Sarason, S.B. (1974). The Psychological Sense Of Community: Prospects For A Community Psychology. San Francisco: CA: Jossey-Bass Publishers.

Sharpley, R. (2002). Tourism and Development: Concepts and Issues. Multilingual Matters Limited.

Singh, S., Timothy, D.J. and Dowling, R.K. (Eds.). (2003). Tourism in Destination Communities.Cambridge, USA: CABI publishing.

Theron, F. (2005). Trends in Micro-Level Development. Pretoria: J. L. van Schaik Publishers.

WTTC. (2008). Progress and Priorities 2008/2009, World Travel and Tourism Council. and Hospitality. 1(S1), S17-S21. https://doi.org/10.51483/IJTH.1.S1.2021.S17-S21. 